Costa, CC, Ferreira, EF, Silva, AS, Leite, DT, Silva, DSO \& Medeiros, AC. (2020) Use of substrates in the development of melon Research, Society and Development, 9(7): 1-14, e717974712.

\title{
Utilização de substratos orgânicos no desenvolvimento de meloeiro
} Use of substrates in the development of melon

\section{Uso de sustratos en el desarrollo del melón}

Recebido: 19/05/2020 | Revisado: 20/05/2020 | Aceito: 25/05/2020 | Publicado: 06/06/2020

\section{Caciana Cavalcanti Costa}

ORCID: https://orcid.org/0000-0003-2598-466X

Universidade Federal de Campina Grande, campus Pombal, Brasil

E-mail: costacc@ccta.ufcg.edu.br

Elisdianne Freires Ferreira

ORCID: https://orcid.org/0000-0002-1056-2985

Universidade Federal de Campina Grande, campus Pombal, Brasil

E-mail: diannefreires@ hotmail.com

Amison de Santana Silva

ORCID: https://orcid.org/0000-0002-9945-4680

Universidade Federal de Campina Grande, campus Pombal, Brasil

E-mail:amison19@hotmail.com

Delzuite Teles Leite

ORCID: https://orcid.org/0000-0002-8749-3615 Universidade Federal do Recôncavo da Bahia, Brasil E-mail:elzuiteteles@gmail.com

Débora Samara Oliveira e Silva

ORCID: https://orcid.org/0000-0001-5266-3584

Universidade Federal de Campina Grande, campus Pombal, Brasil E-mail:debora_samara2008@hotmail.com

Aline Carla de Medeiros

Universidade Federal de Campina Grande, campus Pombal, Brasil ORCID: https://orcid.org/0000-0002-0161-3541 E-mail: alinecarla.edu@gmail.com 


\section{Resumo}

O objetivo da pesquisa foi avaliar o desempenho de plantas de melão produzidas em diferentes substratos. Foi utilizada a cultivar de melão híbrido "Ropey King” F1, submetidas aos seguintes tratamentos: $\mathrm{T} 1=$ Substrato Comercial; $\mathrm{T} 2$ = esterco caprino e solo $(3: 1 \mathrm{v} / \mathrm{v})$; T3 = esterco ovino e solo $(3: 1 \mathrm{v} / \mathrm{v}) ; \mathrm{T} 4=$ esterco bovino e solo $(3: 1 \mathrm{v} / \mathrm{v}) ; \mathrm{T} 5=$ composto orgânico e solo (3:1 v/v); T6 = húmus de minhoca e solo (3:1v/v). O delineamento empregado foi em blocos casualizados com seis tratamentos e quatro repetições. As variáveis analisadas foram: tempo médio de emergência, número de folhas, altura da parte aérea, volume da raiz, estabilidade do torrão, massa fresca da parte aérea, de raízes e total, massa seca da parte aérea, de raízes e total. Pelas avaliações, os substratos alternativos a base de esterco ovino e solo e húmus de minhoca foram os que promoveram melhor desempenho inicial das plantas de melão constatado pelas características, altura da parte aérea, volume da raiz, massa fresca da parte aérea, da raiz e total, massa seca da parte aérea, da raiz e total.

Palavras-chave: Cucumis melo L.; Agricultura sustentável; Nutrientes.

\section{Abstract}

The objective was to evaluate the performance of melon plant produced in different substrates. The melon hybrid variety used was "Ropey King" F1, submitted to the following treatments: $\mathrm{T} 1=$ Commercial substrate; $\mathrm{T} 2=$ goat manure and soil $(3: 1 \mathrm{v} / \mathrm{v}) ; \mathrm{T} 3=$ sheep manure and soil $(3: 1 \mathrm{v} / \mathrm{v}) ; \mathrm{T} 4=$ bovine manure and soil $(3: 1 \mathrm{v} / \mathrm{v}) ; \mathrm{T} 5=$ organic compound and soil $(3: 1 \mathrm{v} / \mathrm{v}) ;$ T6 $=$ earthworm humus and soil $(3: 1 \mathrm{v} / \mathrm{v})$. The design used was in randomized blocks with six treatments and four replications. The variables analyzed were: average emergence time, number of leaves, and height of the aerial part, root volume, root ball stability, fresh mass of the aerial, root and total parts, dry mass of the aerial, roots and total parts. According to the evaluations, the alternative substrates based on sheep manure and soil, and earthworm humus were the ones that promoted the best initial performance of the melon plant verified by the characteristics, height of the aerial part, volume of the root, fresh mass of the aerial, root and total parts, and dry mass of the aerial, roots and total parts.

Keywords: Cucumis melo L.; Sustainable Agriculture; Nutrients.

\section{Resumen}

El objetivo fue evaluar el rendimiento de las plantas de melón producidas en diferentes sustratos. Se utilizó la variedad híbrida de melón "Ropey King" F1, sometida a los siguientes tratamientos: $\mathrm{T} 1=$ sustrato comercial; $\mathrm{T} 2=$ estiércol de cabra y tierra $(3: 1 \mathrm{v} / \mathrm{v}) ; \mathrm{T} 3=$ 
estiércol de oveja y tierra $(3: 1 \mathrm{v} / \mathrm{v}) ; \mathrm{T} 4=$ estiércol bovino y tierra $(3: 1 \mathrm{v} / \mathrm{v}) ; \mathrm{T} 5=$ compost orgánico y suelo $(3: 1 \mathrm{v} / \mathrm{v})$; T6 = humus de lombriz de tierra y suelo $(3: 1 \mathrm{v} / \mathrm{v})$. El diseño utilizado fue en bloques al azar con seis tratamientos y cuatro repeticiones. Las variables analizadas fueron: tiempo de emergencia medio, número de hojas, altura de la parte aérea, volumen de la raíz, estabilidad del cepellón, masa fresca de la parte aérea, raíces y total, masa seca de la parte aérea, raíces y total. Según las evaluaciones, los sustratos alternativos a base de estiércol de oveja y humus de lombriz y tierra fueron los que promovieron el mejor rendimiento inicial de las plantas de melón verificadas por las características, altura de la parte aérea, volumen de la raíz, masa fresca de la parte aérea, de la raíz y masa seca total, aérea, radical y total.

Palabras clave: Cucumis melo L.; Agricultura sostenible; Nutrientes.

\section{Introdução}

Para desenvolver uma agricultura mais sustentável e limpa, o uso de resíduos orgânicos como fonte de nutrientes e matéria orgânica para a produção agrícola tem um importante impacto econômico (Farias et al. 2019). Além disso, esses resíduos podem fornecer suporte a produção garantido o fornecimento de nutrientes e ampliando as taxas de germinação e crescimento.

Dentre os fatores que influenciam diretamente no desempenho agronômico de hortaliças, destaca-se a produção adequada de mudas (Zeist et al., 2017). Estas devem apresentar uniformidade, sanidade e bom desenvolvimento de parte aérea e sistema radicular, a fim de manter o desenvolvimento satisfatório quando transplantadas, e capacidade de resistir a possíveis condições adversas no campo (Caldeira et al., 2008; Correia et al., 2013). Alémdisso, ressalta-se a importância da qualidade das sementes, material genético utilizado, ambiente de produção, recipientes e substratos.

Dentre as espécies que por muito tempo foram implantadas no campo por semeadura direta e hoje está fazendo uso da produção de mudas em bandejas por suas inúmeras vantagens está o melão, que devido o crescimento nos últimos anos das áreas produtivas na região Nordeste, merece atenção, necessitando de estudos sobre as formas de seu manejo e a busca pela adequação das técnicas produtivas, gerando conhecimentos capazes de dar suporte quantitativo e qualitativo para manter o abastecimento do mercado interno e aumentar suas exportações para outros continentes. 
O meloeiro é pertencente à família Curcubitaceae, gênero Cucumis e espécie Cucumis melo L. É uma olerícola muito apreciada e de grande popularidade no mundo, tendo ocupado em 2018, uma área de 23,324 mil ha, com uma produção de 581.478 mil toneladas de frutos (FAO, 2019). O melão é uma hortaliça que teve seu cultivo comercial iniciado no Brasil na década de 60, e desde então, vem ganhando em importância econômica. Há seis grupos botânicos, entre os quais, o Cantaloupensis, ao qual pertence o melão rendilhado (Cucumis melo var. cantalupensis Naud.) (Rizzo; Braz, 2004).

Em 2018, essa cultura produziu 540.229 toneladas de frutas frescas, das quais 342.629 toneladas foram destinadas ao mercado interno e 197.600 toneladas em nível de exportação de frutas frescas no Brasil. O principal produtor é o estado do Rio Grande do Norte, com mais de 50\% da produção destinado à Holanda, Reino Unido e Espanha (Beling, 2018; Queiroga et al. 2020).

Assim, pela expressão do uso desta cultura tanto na alimentação como na economia da região Nordeste, necessário se faz realizar estudos referentes às diversas etapas dos seus sistemas produtivos, buscando maximizar o lucro dos produtores com a redução dos custos de produção.

O objetivo da pesquisa foi avaliar o desenvolvimento inicial de plantas de meloeiro em substratos obtidos através da associação entre materiais orgânicos: estercos caprino, bovino e ovino, jurema (Mimosa hostilis) além de húmus de minhoca e estrato comercial Basaplant.

\section{Metodologia}

O estudo foi realizado na Universidade Federal de Campina Grande/CCTA campus Pombal-PB, em casa de vegetação coberta com filme transparente AUV 0,15 mm. O experimento foi utilizado sombrite com $50 \%$ de sombreamento.

O município de Pombal está localizado nas coordenadas geográficas: Latitude Sul $6^{\circ} 46$ e Longitude Oeste $37^{\circ} 47$ e possui uma altitude média de $184 \mathrm{~m}$. A temperatura média do município é de $28^{\circ} \mathrm{C}$, com médias mensais oscilantes, entre $25^{\circ} \mathrm{C}$, nos meses de julho/agosto, e de $27^{\circ} \mathrm{C}$ nos meses de janeiro/fevereiro.

No estudo, foram avaliados substratos resultantes das misturas entre materiais orgânicos (estercos caprino, bovino e ovino, composto orgânico de esterco bovino e jurema (Mimosa hostilis)) e húmus de minhoca) e solo, utilizando a proporção de 3:1 (v/v), além do substrato comercial Basaplant. 
No preparo do substrato, foram realizados tratamentos fitossanitários (solarização) dos materiais utilizando a metodologia de Souza; Resende (2006). Os materiais foram dispostos em camadas e em seguida umedecidos mantendo a umidade em torno de 50 a $60 \%$, foram colocados em sacos plásticos sobre a luz solar por trinta dias, sendo revirados diariamente. Após a solarização os materiais foram misturados e os substratos foram autoclavados a uma temperatura de $120^{\circ} \mathrm{C}$ à pressão de $1,0 \mathrm{~atm}$ durante 1 hora.

Para a semeadura, os substratos foram distribuídos sobre as bandejas de 200 células. Cada célula recebeu uma semente do híbrido de melão da cultivar "ROPEY KING" F1. Após a semeadura, as bandejas foram deixadas de forma casualizadas, sob casa de vegetação em bancadas de madeira, com altura de 1,0 m, para facilitar os tratos culturais e a poda natural das raízes.

As plantas receberam irrigação, que foi realizada manualmente utilizando regadores adaptados a ocasião, observando a necessidade de se manter a umidade.

Foram utilizados os seguintes tratamentos: T1 (Substrato comercial basaplant); T2 (esterco caprino e solo); T3 (esterco ovino e solo); T4 (esterco bovino e solo); T5 (composto orgânico e solo) e T6 (húmus de minhoca e solo).

Cada unidade experimental foi constituída de 200 células da bandeja, considerando área útil as 100 das 200 células da bandeja de poliestireno, porém considerou-se área útil, para avaliação dos dados as 64 plantas centrais. O delineamento empregado foi em blocos casualizados, com seis tratamentos e quatro repetições.

As avaliações físicas e químicas dos substratos, foram realizadas no laboratório de solos e nutrição de plantas da UAGRA/CCTA/UFCG, de acordo com a metodologia da EMBRAPA (Donagema et al., 2011). (Tabela 1).

As amostragens foram realizadas aos 30 dias após a semeadura (DAS) e as variáveis analisadas foram: tempo médio de emergência - obtido pelo número de células que possuíam plântulas emergidas, ao final foi realizado o cálculo utilizando a fórmula expressa em dias, segundo Ferreira e Borghetti (2004), com adaptações; número de folhas - foram contabilizadas todas as folhas expandidas das plantas; altura de plantas - obtida com auxílio de um paquímetro digital, fazendo a medição da base do caule até a máxima altura das folhas, com os dados expressos em mm; volume das raízes - obtido pelo volume excedido após emergência das raízes em uma proveta de $100 \mathrm{ml}$ com $50 \mathrm{ml}$ de água; e estabilidade do torrão - obtida ao retirar as plantas das células, seguindo o padrão de notas de Gruszynski (2002) onde: 1 = quando mais de $50 \%$ do torrão ficar retido no recipiente; 2 = o torrão se destacar do recipiente, mas não permanecer coeso e 3= quando todo o torrão for destacado do recipiente e 
mais de $90 \%$ dele permanece coeso, para as duas culturas; massa fresca da parte aérea - as plantas foram pesadas em balança semianalítica, com valores expressos em gramas; massa fresca das raízes - estas foram lavadas e pesadas em balança semianalítica, com valores expressos em gramas; massa fresca total - foi obtida pelo somatório da massa fresca da parte aérea e da raiz; massa seca da parte aérea - após as plantas serem pesadas e lavadas, foram colocadas em sacos de papel e mantidas em estufa de circulação forçada de ar a $60^{\circ} \mathrm{C}$, até obterem peso constante, depois foram pesadas em balança semianalítica, com valores expressos em gramas; massa seca das raízes - obtida pela secagem das mesmas, em estufa de ar a $60^{\circ} \mathrm{C}$; massa seca total das plantas - obtida pelo somatório da massa seca da parte aérea e da raiz.

Para análise dos dados do experimento, foi realizada a análise de variância simples pelo Teste F e quando significativa para a comparação das médias foi empregado o Teste de Tukey a $5 \%$ de probabilidade.

\section{Resultados e Discussão}

A Tabela 1, apresenta os dados físicos e químicos dos substratos utilizados nos tratamentos. 
Tabela 1. Análises físicas e químicas dos substratos, Pombal, UFCG/CCTA.

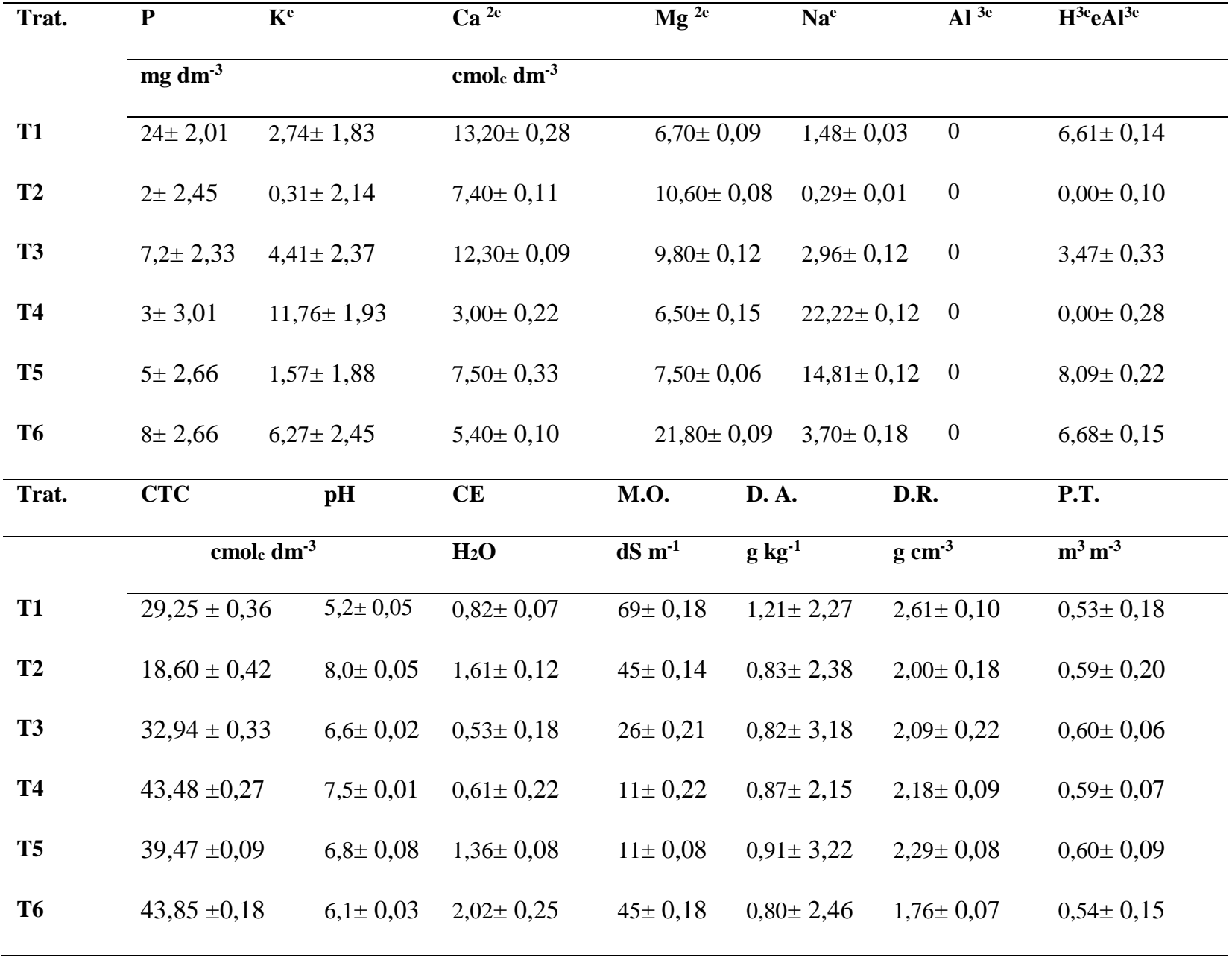

$\mathrm{T} 1$ = Substrato Comercial Basaplant; $\mathrm{T} 2$ = esterco caprino e solo; $\mathrm{T} 3$ = esterco ovino e solo; $\mathrm{T} 4$ = esterco bovino e solo; $\mathrm{T} 5=$ composto orgânico a base de esterco bovino e jurema e solo; T6 = Húmus de minhoca e solo. Trat. = Tratamento. CTC. = Capacidade de troca catiônica. $\mathrm{pH}=$ Potencial Hidrogeniônico. $\mathrm{CE}=$ Condutividade Elétrica. D.A. =Densidade aparente. D.R. =Densidade real. P.T.= Porosidade Total.

Para a característica tempo médio de emergência (TME), verificou-se que houve efeito significativo entre os tratamentos. O menor tempo médio de emergência foi observado nos substratos esterco bovino e solo (T4) e composto orgânico e solo (T5), com médias de 7,6 e 8,6 dias (Tabela 2). Durante as observações verificou-se que a emergência das plântulas teve início quatro dias após a semeadura (DAS), sendo observada em cinco substratos, exceto no húmus de minhoca e solo que só começou a emergir aos cinco DAS, portanto, os substratos alternativos que proporcionaram maior tempo de emergência nas plantas foram: T2 (esterco caprino e solo); T3 (esterco ovino e solo) e T6 (Húmus de minhoca e solo) que apresentaram similaridade ao Substrato Comercial Basaplant (Tabela 2). 
Tabela 2. Tempo médio de emergência (TME), número de folhas (NF), altura da parte aérea (APA), volume de raiz (VR) e estabilidade do torrão (ET) de plantas de melão, em função dos diferentes substratos, Pombal, UFCG/CCTA.

\begin{tabular}{cccccc}
\hline Trat & $\begin{array}{c}\text { TME } \\
(\text { dias })\end{array}$ & NF & $\begin{array}{c}\text { APA } \\
(\mathbf{m m})\end{array}$ & $\begin{array}{c}\text { VR } \\
(\mathbf{m l})\end{array}$ & ET \\
\hline T1 & $11,37 \mathrm{ab}$ & $3,72 \mathrm{a}$ & $42,5 \mathrm{c}$ & $8,50 \mathrm{c}$ & $2,85 \mathrm{a}$ \\
T2 & $13,83 \mathrm{a}$ & $4,57 \mathrm{a}$ & $59,2 \mathrm{bc}$ & $11,75 \mathrm{ab}$ & $2,97 \mathrm{a}$ \\
T3 & $13,58 \mathrm{a}$ & $3,52 \mathrm{a}$ & $99,9 \mathrm{a}$ & $13,00 \mathrm{a}$ & $2,95 \mathrm{a}$ \\
T4 & $7,60 \mathrm{c}$ & $4,05 \mathrm{a}$ & $60,9 \mathrm{bc}$ & $9,75 \mathrm{bc}$ & $3,00 \mathrm{a}$ \\
T5 & $8,56 \mathrm{bc}$ & $3,70 \mathrm{a}$ & $76,5 \mathrm{ab}$ & $9,50 \mathrm{c}$ & $3,00 \mathrm{a}$ \\
T6 & $11,62 \mathrm{a}$ & $4,00 \mathrm{a}$ & $76,5 \mathrm{ab}$ & $12,00 \mathrm{a}$ & $3,00 \mathrm{a}$ \\
\hline $\mathbf{C . V}(\%)$ & 11,14 & 17,10 & 17,57 & 8,77 & 2,80 \\
\hline
\end{tabular}

$\mathrm{T} 1$ = Substrato Comercial Basaplant; $\mathrm{T} 2$ = esterco caprino e solo; $\mathrm{T} 3$ = esterco ovino e solo; $\mathrm{T} 4=$ esterco bovino e solo; $\mathrm{T} 5=$ composto orgânico a base de esterco bovino e jurema e solo; T6 = Húmus de minhoca e solo. *Médias seguidas pela mesma letra na coluna não diferem pelo teste de Tukey a 5\%. Trat. = Tratamento.

Comportamento semelhante ao observado por Pires et al. (2006) que testando diferentes substratos a base de solo e bagaço de cana-de-açúcar na emergência de plântulas de melão, verificaram que o substrato comercial (Plantimax) obteve desempenho inferior aos substratos alternativos para tempo médio de emergência.

As plantas dos substratos T4 e T5 emergiram em média, cerca de sete a oito dias após a semeadura. De acordo com as características físicas presentes nestes substratos não há diferença entre estas.

Para o número de folhas (Tabela 2) não houve diferença significativa entre os tratamentos, porém pelos valores absolutos verifica que as plantas produzidas nos substratos com esterco caprino e solo (T2), bovino e solo (T4) e húmus de minhoca e solo (T6) tenderam a serem superiores ao substrato comercial Basaplant (T1), esterco ovino e solo (T3) e ao composto orgânico e solo (T5). Apesar do substrato esterco caprino e solo (T2) ter demorado a emergir pelo TME, observa-se que as plântulas se desenvolveram rapidamente atingindo e até ultrapassando a taxa de crescimento dos outros substratos.

Tessaro et al. (2013), afirma que o número de folhas é um dos parâmetros mais importantes a serem avaliados no cultivo de mudas, pois um bom desenvolvimento da porção aérea permite à planta uma maior capacidade de fotossíntese.

Para altura da parte aérea houve efeito significativo entre os tratamentos, sendo T3 (esterco ovino e solo); T5 (composto orgânico) e T6 (húmus de minhoca e solo) os substratos que 
promoveram melhor desempenho das plantas de melão. Provavelmente as características físicas destes substratos sejam influenciadoras, ou seja, os substratos com uma menor densidade, maior porosidade total e maior espaço de aeração favoreceram o desenvolvimento da parte aérea da planta (Tabela 1). Lima et al. (2007) avaliando o desempenho de plantas de melão em função de diferentes proporções de substratos a base de serrapilheira (SER) e fibra de coco (FBC), observaram que para altura da parte aérea o substrato com $100 \%$ de SER, promoveu o melhor desempenho das plantas diferindo estatisticamente dos com $100 \%$ de FBC, $75 \%$ de FBC e $25 \%$ de SER, $50 \%$ de FBC e $50 \%$ de SER, $25 \%$ de FBC e $75 \%$ de SER.

Estatisticamente, para o volume da raiz (Tabela 2) constatou-se que o substrato a base de esterco ovino e solo (T3) foi o que promoveu maiores valores, não diferindo do húmus de minhoca e solo (T6) e do esterco caprino e solo (T2). Isso pode ter ocorrido devido aos baixos valores de densidade real encontrados nesses substratos, o que contribuiu com a maior porosidade e desenvolvimento das raízes e consequentemente, com o maior volume das mesmas.

Para estabilidade do torrão as médias não diferiram estatisticamente, pelos valores absolutos verificou-se que com a aplicação de todos os tratamentos as notas foram semelhantes a 3, ou seja, o torrão foi formado e destacado da célula mantendo mais de $90 \%$ de sua formação coesa, que é desejável na ocasião do substrato ser utilizado para formação de mudas, pois no transplantio, mudas com raízes agregadas em torrão coeso tem um melhor pegamento no campo, uma vez que a não destruição das raízes não causa interferências na absorção de água e nutrientes bem como evita a entrada de patógenos de solo por fissuras radiculares.

Os substratos esterco caprino e solo (T2), esterco ovino e solo (T3), bovino e solo (T4), composto orgânico e solo (T5) e húmus de minhoca e solo (T6), para a massa fresca da parte aérea (Tabela 3) promoveram desempenho superior ao substrato comercial Basaplant (T1). Através desses resultados, é possível observar que houve uma interação positiva entre os substratos, o solo e a planta, garantindo condições fisiológicas adequadas ao desenvolvimento da planta. Contrariando os resultados de Aragão et al. (2011), que testando substratos a base de solo e bagaço de cana-de-açúcar na produção de plantas de melão, observaram diferença significativa entre os tratamentos para massa fresca da parte aérea, sendo o substrato comercial Plantimax o que apresentou melhor desempenho. 
Tabela 3. Massa fresca da parte aérea (MFPA), massa seca da parte aérea (MSPA), massa fresca da raiz (MFR), massa seca da raiz (MSR), massa fresca total (MFT) e massa seca total (MST) de plantas de melão, em função de diferentes substratos, Pombal, UFCG/CCTA.

\begin{tabular}{|c|c|c|c|c|c|c|}
\hline Trat. & $\begin{array}{c}\text { MFPA } \\
(\mathrm{g})\end{array}$ & $\begin{array}{c}\text { MSPA } \\
\text { (g) }\end{array}$ & $\begin{array}{c}\text { MFR } \\
\text { (g) }\end{array}$ & $\begin{array}{c}\text { MSR } \\
(\mathrm{g})\end{array}$ & $\begin{array}{c}\text { MFT } \\
(\mathrm{g})\end{array}$ & $\begin{array}{c}\text { MST } \\
\text { (g) }\end{array}$ \\
\hline T1 & $4,94 \mathrm{c}$ & $0,72 \mathrm{c}$ & $3,84 \mathrm{c}$ & $0,23 \mathrm{~b}$ & $8,50 \mathrm{c}$ & $0,95 \mathrm{c}$ \\
\hline $\mathbf{T} 2$ & $10,58 \mathrm{~b}$ & $1,47 \mathrm{~b}$ & $6,14 \mathrm{ab}$ & $0,27 \mathrm{~b}$ & $16,72 \mathrm{~b}$ & $1,74 \mathrm{~b}$ \\
\hline $\mathbf{T 3}$ & $17,99 \mathrm{a}$ & $2,57 \mathrm{a}$ & $8,40 \mathrm{a}$ & $0,38 \mathrm{a}$ & $26,38 \mathrm{a}$ & $2,96 \mathrm{a}$ \\
\hline T4 & $13,10 \mathrm{ab}$ & $1,39 \mathrm{~b}$ & $5,77 \mathrm{ab}$ & $0,26 \mathrm{~b}$ & $18,87 \mathrm{~b}$ & $1,65 \mathrm{~b}$ \\
\hline T5 & $16,84 \mathrm{a}$ & $1,70 \mathrm{a}$ & $6,40 a b$ & $0,30 \mathrm{ab}$ & $23,23 \mathrm{ab}$ & $2,01 \mathrm{~b}$ \\
\hline T6 & $13,55 \mathrm{ab}$ & $1,93 \mathrm{ab}$ & $7,44 \mathrm{a}$ & $0,36 \mathrm{a}$ & $20,98 \mathrm{ab}$ & $2,30 a b$ \\
\hline C.V(\%) & 18,63 & 17,85 & 20,83 & 13,46 & 16,48 & 16,00 \\
\hline
\end{tabular}

$\mathrm{T} 1$ = Substrato Comercial Basaplant; T2 = esterco caprino e solo; $\mathrm{T} 3$ = esterco ovino e solo; $\mathrm{T} 4$ = esterco bovino e solo; T5 = composto orgânico a base de esterco bovino e jurema e solo; T6 = Húmus de minhoca e solo. *Médias seguidas pela mesma letra na coluna não diferem pelo teste de Tukey a 5\%.

Verificou-se para a massa fresca da raiz (Tabela 3) que os substratos esterco ovino e solo (T3) e o húmus de minhoca e solo (T6) promoveram melhor desempenho de plantas em relação ao substrato comercial Basaplant (T1), esse comportamento pode ser atribuído a diferença entre as densidades real (DR), aparente (DA) e, a porosidade total (PT) desses tratamentos (Tabela 1), pois os valores referentes ao substrato comercial foram superiores para DR e DA e inferiores para PT, o que reflete em menor espaço no substrato para o desenvolvimento das raízes. Os substratos T3 e T6 não diferiram estatisticamente do esterco caprino e solo (T2), bovino e solo (T4), composto orgânico e solo (T5), possivelmente a densidade aparente tenha influenciado mais efetivamente, pois os valores da DA para esses substratos, são muito próximos.

Para a variável densidade aparente (DA), foram encontrados valores entre 0,80 e 1,21 g $\mathrm{cm}^{-3}$. Dentro dos valores considerados ideais (Martinez et al., 2002).

Observou-se que para a massa fresca total, os dados apresentaram diferença significativa entre os tratamentos (Tabela 3), onde o esterco ovino e solo (T3), mais uma vez favoreceu o desenvolvimento das plantas, não diferindo, porém, dos tratamentos T5 e T6.

Pelo efeito significativo para a massa seca da parte aérea (MSPA), verifica-se que os substratos esterco ovino e solo (T3) e húmus de minhoca e solo (T6), promoveram médias superiores aos demais tratamentos (Tabela 3). Comportamento semelhante foi observado em 
plantas de melão produzidas em substrato composto de fibra de coco seco e húmus de minhoca na proporção 1:1 e em substrato comercial Plantmax (Bezerra; Bezerra, 2001; Aragão et al., 2011). Entretanto, esse mesmo desempenho foi observado em plantas de meloeiro produzidas em substrato comercial Plantmax (Aragão et al., 2011).

Em relação à massa seca da raiz (Tabela 3), o esterco ovino e solo (T3) e o húmus de minhoca e solo (T6), resultaram no desempenho superior aos demais, sem diferir do composto orgânico e solo (T5). Nesse contexto, o desenvolvimento adequado do sistema radicular infere que, depois de transplantadas, as mudas apresentarão maior capacidade de absorver água e nutrientes, garantindo melhor desenvolvimento da cultura (Vendruscolo et al., 2016)

No que se refere a massa seca total, houve diferença significativa entre os tratamentos (Tabela 3) onde o esterco ovino e solo (T3), e o húmus de minhoca e solo (T6), promoveram médias superiores aos demais tratamentos, favorecendo o melhor desenvolvimento inicial das plantas de melão.

Observou-se pela análise química (Tabela 1) que para o substrato T3 (esterco ovino e solo), bem como para o T4 e T6 os valores médios de pH está dentro da faixa ideal $(6,0$ a 7,5) para a cultura (Embrapa, 2004), faixa esta, na qual há alta disponibilidade do fósforo para absorção pelas plantas (Malavolta, 1997).

\section{Considerações Finais}

Nas condições deste experimento, os substratos alternativos compostos de esterco ovino e solo e húmus de minhoca foram os que promoveram melhor desempenho inicial das plantas de melão constatado pelas características, altura da parte aérea, massa fresca da parte aérea da raiz e total, massa seca da parte aérea, da raiz e total e volume da raiz.

\section{Referências}

Aragão, C. A.; Pires, M.M.M.L.; Batista, P.F. \& Dantas, B.F. (2011). Qualidade de plantas de melão produzidas com diferentes substratos. Revista Caatinga, 4(3): 209-214.

Beling R. R. (ed.). (2018). Brazilian horti \& fruti yearbook. Santa Cruz do Sul: Editora Gazeta Santa Cruz, 96 p. 
Bezerra, F. C. \& Bezerra, G. S. S. (2000). Diferentes substratos para a formação de plantas de meloeiro. In: Congresso Brasileiro de Olericultura, 41. 2000, São Pedro. Resumos ... São Pedro, 2001, p. 294. CD-ROM.

Caldeira, M.V.W.; Rosa, G.N.; Fenilli, T. A.B. \& Harbs, R.M.P. (2008). Composto orgânico na produção de mudas de aroeira-vermelha. Scientia Agraria, Curitiba, 9(1):27-33.

Correia, A.C.G.; Santana, R.C.; Oliveira, M.L.R.; Titon, M.; Ataíde, G.M.; \& Leite, F.P. (2013). Volume de substrato e idade: influência no desempenho de mudas clonais de eucalipto após replantio. Cerne, Lavras, 19(2): 185-191.

Donagema, G. K.; Campos, D.V.C.; Calderano, S. B; Teixeira, W. G.; \& Viana, J.H.M. (2011). Manual de Métodos de Análise de Solo. 2. ed. Rio de Janeiro: Embrapa Solos, 230 p.

EMBRAPA (2004). Empresa de Pesquisa Agropecuária Brasileira. Manual de Segurança e Qualidade para a Cultura do Melão. EMBRAPA, Brasília, 87 p.

FAO - (2019). Food and Agriculture Organization of the United Nations. Crops. 2014. Disponível em: http://faostat.fao.org/site/567/DesktopDefault.aspx ?PageID=567\#ancor. Acesso em: 20 Dez 2019.

Farias, G.A., Costa, A.C., Costa, S.F., Farias, G.A., Pereira, P.H.F. \& Cabral Jr, L.F. (2019). Produção de mudas de maracujazeiro amarelo em substratos contendo resíduos vegetais. Colloquium Agrariae, 15(1), 141-148.

Ferreira, A. G.; Borguetti, F. Germinação do básico ao aplicado. Artmed, Porto Alegre, 2004. $323 \mathrm{p}$.

Gruszynski, C. Resíduo agroindustrial "casca de tungue" como componente de substrato para plantas. 2002. 99 f. Dissertação de Mestrado. UFRGS. Porto Alegre. 2002.

Kämpf, A. N. (2005). Substrato. In: Kämpf, A. N. Produção comercial de plantas ornamentais. 2. ed. Agropecuária, Guaíba, 2005. 254p. 
Lima, C. J. G. S.; Oliveira, F.A.; Medeiros, J.M.; Pontes, N.C.; Oliveira, M.C.T; Almeida Júnior, A. B.; Freire, G.M; Guimarães, I. P. \& Marrocos, S.T.P. (2007). Uso de serrapilheira de Tamarindus indica L. como substrato alternativo na produção de plantas de melão. In: Congresso Brasileiro de Olericultura, 47. 2007, Porto Seguro. Resumos ... Porto Seguro, 2007, p. A278_T79. CD-ROM.

Malavolta, E.; Vitti, G.C. \& Oliveira, S. A. (1999) Avaliação do estado nutricional das plantas. Princípios e aplicações. 2 ed. Potafós, Piracicaba, 1999. 319 p.

Martinez, P. Manejo de substratos para horticultura. In: Furlini, A. M. C. Caracterização, manejo e qualidade de substratos para produção de plantas. IAC, Campinas. p. 53-73, 2002.

Otani, T.; Ae, N. \& Tanaka, M. Phosphorus uptake mechanisms of crop growth in soils with low P status. Soil Science and Plant Nutrition, 42: 553-560. 1996.

Pires, M. M. L.; Batista, P.F.; Santos, J.S.; Santos, M.R.; Santos, G.M \& Aragão, C.A. Emergência de plântulas de melão em diferentes substratos. In: Congresso Brasileiro de Olericultura, 46. 2006. Goiânia. Resumos... Goiânia. p. 1164-1167. 2006. CD-ROM.

Queiroga, R.C.F, Silva, Z.L, Oliveira, O.H, Santos, E.N, Silva, H.L.O, Costa, F.B \& Assis, L.E. (2020). Melon fruit yield and quality as a function of doses and times of biostimulant application. Research, Society and Development. 9(7):1-18. e130973911.

Rizzo, A. A. N \& Braz, L. T. (2004). Desempenho de linhagens de melão rendilhado em casa de vegetação. Horticultura Brasileira. 22:(4) 784-788.

Souza, J. L. \& Resende, P. (2006) Manual de horticultura orgânica. 2 ed. Aprenda fácil, Viçosa, 2006. 843 p.

Tessaro, D.; Matter, J.M.; Kuczman, O.; Furtado, L.F.; Costa, L.A.M. \& Costa, M.S.S.M. Produção agroecológica de mudas e desenvolvimento a campo de couvechinesa. Ciência Rural, 43(5) 831-837, 2013. 
Vendruscolo, E.P.; Martins, A.P.B. \& Seleguini, A. Promoção no desenvolvimento de mudas olerícolas com uso de bioestimulante. Journal of Agronomic Sciences, Umuarama, 5(2) 73 $82,2016$.

Zeist, A.R.; Resende, J.T.V.; Giacobbo, C.L.; Faria, C.M.D.R. \& Dias, D.M. (2017). Graft takes of tomato on other solanaceous plants. Revista Caatinga, 30: 513-520, 2017.

\author{
Porcentagem de contribuição de cada autor no manuscrito \\ Caciana Cavalcanti Costa - 30\% \\ Elisdianne Freires. Ferreira - 30\% \\ Amison de Santana Silva - 10\% \\ Delzuite Teles Leite - $10 \%$ \\ Débora Samara Oliveira e Silva - 10\% \\ Aline Carla de Medeiros - 10\%
}

